\title{
Traumatic cataract surgery in pediatric patients. Experience in a site
}

\author{
Verónica Y. Burgos-Elías, M.D. ${ }^{a}$, Ma. José Marroquín-Sarti, M.D. ${ }^{a}$, Martin A. Zimmermann-Paiz, M.D. ${ }^{a}$, \\ Ana Marissa Ordoñez Rivas, M.D. ${ }^{a}$ and Nancy C. Quezada-del Cid, M.D. ${ }^{a}$
}

\begin{abstract}
Ocular trauma is a significant problem worldwide. Theobjective of this study was to determine the characteristics of patients younger than 14 years who underwent traumatic cataract surgery at the Unit of Pediatric Ophthalmology, Strabismus and Neuro-Ophthalmology "Dra. Ana María Illescas Putzeys" of Hospital de Ojos y Oídos "Dr. Rodolfo Robles V." A retrospective, descriptive, and observational study was carried out to review the medical records of patients who underwent cataract surgery between 2010 and 2015. A total of 54 children underwent traumatic cataract surgery; $75 \%$ were boys; $68 \%$ were in the 6-11-year-old age range. Blunt force trauma was observed in $57.4 \%$. A visual acuity of $20 / 70$ or better was achieved by $68.2 \%$ of patients.
\end{abstract}

Key words: cataracts, pediatrics, trauma, surgery, amblyopia.

http: / / dx.doi.org/10.5546/ aap.2018.eng.216

To cite: Burgos-Elías VY, Marroquín-Sarti MJ, Zimmermann-Paiz MA, et al. Traumatic cataract surgery in pediatric patients. Experience in a site. Arch Argent Pediatr 2018;116(3):216-219. a. Unit of Pediatric Ophthalmology, Strabismus and NeuroOphthalmology "Dra. Ana María Illescas Putzeys" of Hospital de Ojos y Oídos "Dr. Rodolfo Robles V.," Institute of Vision Science (Instituto de Ciencias de la Visión), Meritorious Guatemalan Committee for the Blind and Deaf (Benemérito Comité Pro Ciegos y Sordos de Guatemala), Guatemala.

E-mail address

Verónica Y.Burgos Elías, M.D.: veronicaburgos1@hotmail.com

Funding: None.

Conflict of interest: None.

Received: 5-17-2017

Accepted: 9-19-2017

\section{INTRODUCTION}

Ocular trauma is a significant problem worldwide and is the main cause of non-congenital unilateral blindness in children. The incidence of severe visual impairment or blindness caused by ocular trauma in the pediatric age group ranges from $2 \%$ to $14 \%$ according to the data compiled in different studies. ${ }^{1}$

Based on this, worldwide there are 3.9 million people with bilateral low vision or blindness and more than 18 million people with unilateral visual impairment. ${ }^{2}$ Data from developing countries are scarce.

Developing cataracts is one of the serious consequences of an ocular trauma in adults and children. Cataracts make up a special category because they occur in association with other ocular alterations, such as corneal or iris damage, vitreous hemorrhage, and retinal detachment. ${ }^{3}$

The objective of this study was to determine the characteristics of patients younger than 14 years who underwent traumatic cataract surgery at the Unit of Pediatric Ophthalmology, Strabismus and Neuro-Ophthalmology “Dra. Ana María Illescas Putzeys" of Hospital de Ojos y Oídos "Dr. Rodolfo Robles V."

\section{MATERIAL AND METHODS}

This was a retrospective, descriptive, and observational study. The medical records were reviewed once the institution gave its permission.

The following data were collected from the records of patients who underwent traumatic cataract surgery between 2010 and 2015: age, sex, type of injury (blunt or sharp force trauma), time interval between trauma and surgery, intraocular lens (IOL) implantation or not, amblyopia treatment or not, postoperative follow-up, and complications. For patients who completed postoperative follow-up for 1 year, pre- and postoperative visual acuity (VA) were documented (measured using a Snellen chart for verbal patients and the central, steady, and maintained fixation on a target [CSM] for preverbal patients). 
The surgical technique was that described in Orbis International's Cataracts in Childhood, ${ }^{4}$ which consists in creating the scleral tunnel, aspirating the cataract and subsequent posterior capsulotomy with anterior vitrectomy. An IOL was implanted in patients older than 2 years who had an adequate capsular support during the same surgical procedure.

A $20 / 70$ or better VA 1 year after the surgery was considered an adequate visual outcome based on most studies published regarding traumatic cataract in children..$^{5-7}$

Patients who underwent surgery and showed a two-line difference between their eyes received amblyopia treatment. It consisted in patching the good eye for at least 8 hours a day with regular controls ( 1 week for each year old) and completing at least 6 months of treatment.

Data were recorded and analyzed in a speciallydesigned sheet using the Epi Info software (Database and statistics software for public health professionals, Centers for Disease Control and Prevention 2008).

\section{RESULTS}

During the study period, 207 patients underwent cataract surgery. Of these, $54(26 \%)$ corresponded to traumatic cataract surgery.

Table 1 is a summary of the characteristics of the
54 patients. Of them, 41 were boys $(75 \%)$, and $83 \%$ came from a rural area. The highest percentage of patients was in the 6-11-year-old age range (68\%).

The main type of trauma was blunt force trauma in 31 patients $(57.4 \%)$ and the trauma mechanism was mostly unknown in 16 patients $(29 \%)$. Secondly, a tree branch was the cause in 11 patients $(20 \%)$. Other objects: sharp objects (wire, needle, pencil, scissors) in $16.7 \%$, stones in $11.1 \%$, and others (belt, blow, ball, lemon, coffee bean) in $23.2 \%$.

The time interval between the trauma and the cataract surgery was more than 30 days in $87 \%$ of patients.

In this study, no statistically significant relationship ( $p=0.44)$ was observed between a poor visual outcome and sharp force trauma $(42.9 \%)$. No statistically significant relationship ( $p=0.44)$ was observed either when comparing a good visual outcome and blunt force trauma $(53.3 \%)$.

Only 22 patients $(40.7 \%)$ completed 1 year of follow-up after the surgery.

Table 2 is a summary of preoperative VA in these 22 patients by age range.

Table 3 shows the final VA (after 1 year of follow-up) by age range.

The time interval between the trauma and the cataract surgery of the patients who completed

TABLE 1.Total number of patients who underwent traumatic cataract surgery in the 2010-2015 period

\begin{tabular}{|c|c|c|c|c|c|c|c|c|c|c|c|}
\hline \multirow{2}{*}{$\begin{array}{l}\text { Age } \\
\text { (years old) }\end{array}$} & \multicolumn{2}{|c|}{ Sex } & \multirow{2}{*}{ Total (\%) } & \multicolumn{6}{|c|}{ Time interval between trauma and surgery (days) } & \multirow[b]{2}{*}{ Rural } & \multirow[b]{2}{*}{ Urban } \\
\hline & $\mathbf{M}$ & $\mathbf{F}$ & & Blunt force & Sharp force & $0-2$ & $3-7$ & $8-30$ & $>30$ & & \\
\hline $0-2$ & 1 & 0 & $1(1.9)$ & 0 & 1 & 0 & 0 & 0 & 1 & 1 & 0 \\
\hline $3-5$ & 8 & 3 & $11(20.4)$ & 5 & 6 & 0 & 0 & 2 & 9 & 10 & 1 \\
\hline $6-8$ & 12 & 7 & $19(35.2)$ & 10 & 9 & 0 & 1 & 1 & 17 & 17 & 2 \\
\hline 9-11 & 15 & 3 & $18(33.3)$ & 13 & 5 & 0 & 0 & 0 & 18 & 13 & 5 \\
\hline $12-14$ & 5 & 0 & $5(9.4)$ & 3 & 2 & 1 & 1 & 1 & 2 & 4 & 1 \\
\hline Total $(\%)$ & $41(75.9)$ & $13(24.1)$ & $54(100)$ & $31(57.4)$ & $23(42.6)$ & 1 (1.9) & $2(3.7)$ & $4(7.4)$ & $47(87.0)$ & $45(83.3)$ & 9 (16.7) \\
\hline
\end{tabular}

M: male; F: female.

TABLE 2. Preoperative visual acuity in patients who completed follow-up for 1 year

\begin{tabular}{lccccccc}
\hline & \multicolumn{5}{c}{ Visual acuity } & \\
\cline { 2 - 6 } Age (years old) & $\mathbf{2 0 / 2 0 - 2 0 / 4 0}$ & $\mathbf{2 0 / 5 0 - 2 0 / 7 0}$ & $\mathbf{2 0 / 1 0 0 - 2 0 / 2 0 0}$ & $\mathbf{2 0 / 4 0 0 - M M}$ & PL & NPL & Total (\%) \\
\hline $0-2$ & 0 & 0 & 0 & 0 & 1 & 0 & $1(4.4)$ \\
$3-5$ & 0 & 0 & 0 & 3 & 3 & 0 & $6(27.7)$ \\
$6-8$ & 0 & 0 & 2 & 2 & 2 & 0 & $6(27.3)$ \\
$9-11$ & 0 & 0 & 1 & 4 & 0 & 0 & $5(22.7)$ \\
$12-14$ & 0 & 0 & 1 & 0 & 3 & 0 & $4(18.2)$ \\
Total $(\%)$ & 0 & 0 & $4(18.2)$ & $9(40.9)$ & $9(40.9)$ & 0 & $22(100)$ \\
\hline
\end{tabular}

HM: hand motion; LP: light perception; NLP: no light perception. 
follow-up was more than 30 days in 17 patients $(77.3 \%)$.

In this series, an IOL was implanted in $77.3 \%$ patients. An adequate visual outcome, which was statistically significant $(p=0.01)$, was observed in 14 of these children (63.6\%). Among the 5 patients with aphakia, only 1 had a good visual outcome (20/25 VA) related to the constant wearing of glasses.

Among the 22 patients, only $7(31.8 \%)$ required amblyopia treatment.

Among the patients who completed followup, only $6(27.3 \%)$ developed complications: glaucoma (in 1 patient with aphakia and in 1 with pseudoaphakia), rupture of a haptic in the IOL in 1 patient resulting in aphakia, retinal detachment in 1 patient, severe corneal opacity in 1 patient, and endophthalmitis (present before the surgery) in 1 patient, who was the only one with final VA of no light perception.

\section{DISCUSSION}

The visual outcome in pediatric patients with traumatic cataract surgery depends on multiple factors, such as age at the time of the ocular trauma, the type of injury, and treatment (surgical procedure, correction of the refractive error, amblyopia treatment, and treatment adherence).

In this review, most patients were boys (75.9\%), which was consistent with most studies conducted in Latin America, Europe, and Asia, where this percentage ranged from $70 \%$ to $85 \% .^{5-7}$ This may be because boys usually do more dangerous and forceful activities. ${ }^{3,8}$

The age group that showed a greater relationship was the 6-11-year-old group, as observed in other countries that reported an average age of 6.6-10 years. ${ }^{5-7}$

The most common type of trauma was blunt force trauma in $57.4 \%$ and sharp force trauma in $42.6 \%$; this was consistent with what has been reported in other studies, which reported that blunt force trauma ranged from $48 \%$ to $87 \%$ and sharp force trauma ranged from $19.6 \%$ to $39 \% .39,10$

The objects causing the trauma included a tree branch in $20 \%$ of patients, similar to a study that reported $28 \%$, sharp objects (wire, needle, pencil, scissors) in $39 \%$ of cases reported, higher than the $16.7 \%$ reported in this series. ${ }^{3}$

Most studies consider that a 20/70 or better VA is an adequate visual outcome..$^{5-7}$ A $20 / 40$ or better VA was reported in $45-70 \%$ of children following cataract surgery. ${ }^{3,6,711}$ In this series, 15 patients who completed 1 year of follow-up achieved a better than 20/70 VA. Of these, 12 patients had a better than 20/40 VA and 3, 20/50-20/70 VA.

A good visual outcome was probably due to trauma sequelae not causing relevant structural changes both at the anterior level (cornea) or the posterior level (retina).

As in other publications, in our study, most children attended the first visit more than 30 days after the trauma occurred. ${ }^{6,7,12}$

Surgical treatment with IOL implantation for children undergoing traumatic cataract surgery is effective for visual rehabilitation. ${ }^{11,13}$ In Israel, statistical significance was observed in relation to the poor visual outcome in children with aphakia compared to those with pseudoaphakia. ${ }^{11}$

Among 54 patients, 32 did not complete 1 year of follow-up, which may be because most lived in a rural area (distance from the capital city, difficult access to communities, extreme poverty). This was a factor of poor prognosis, considering the need for amblyopia treatment and optical correction in some of these patients.

In one of the studies included in the review, the following measures are recommended for ocular trauma management: ${ }^{8}$

a) To rapidly determine the scope of the injury to prevent further damage.

TABLE 3. Postoperative visual acuity in patients who completed follow-up for 1 year

\begin{tabular}{|c|c|c|c|c|c|c|c|}
\hline \multirow[b]{3}{*}{ Age (years old) } & \multicolumn{6}{|c|}{ Visual acuity } & \multirow[b]{3}{*}{ NLP } \\
\hline & \multicolumn{6}{|c|}{ Postoperative (N: 22) } & \\
\hline & $20 / 20-20 / 25$ & $20 / 30-20 / 40$ & 20/50-20/70 & $20 / 100-20 / 200$ & 20/400-MM & LP & \\
\hline $0-2$ & 0 & 1 & 0 & 0 & 0 & 0 & 0 \\
\hline $3-5$ & 0 & 5 & 1 & 0 & 0 & 0 & 0 \\
\hline $6-8$ & 1 & 2 & 0 & 2 & 1 & 0 & 0 \\
\hline $9-11$ & 2 & 0 & 1 & 0 & 1 & 1 & 0 \\
\hline $12-14$ & 0 & 1 & 1 & 1 & 0 & 0 & 1 \\
\hline Total (\%) & $3(13.6)$ & $9(40.9)$ & $3(13.6)$ & $3(13.6)$ & $2(9.1)$ & $1(4.6)$ & $1(4.6)$ \\
\hline
\end{tabular}

HM: hand motion; LP: light perception; NLP: no light perception. 
b) If there is suspicion of eyeball or eyelid laceration, a plastic shell (or paper cup secured with tape) should be placed to prevent rubbing.

c) Immediate referral to a specialized facility.

\section{CONCLUSION}

The age at which the trauma incidence was higher was the 6-11-year-old age group; male gender was most commonly affected; and most patients suffered blunt force trauma. In this series, 15 patients who underwent traumatic cataract surgery and completed 1 year of followup achieved a $20 / 70$ or better VA.

\section{REFERENCES}

1. Al-Mahdi HS, Bener A, Hashim SP. Clinical pattern of pediatric ocular trauma in fast developing country. Int Emerg Nurs 2011;19(4):186-91.

2. Abbott J, Shah P. The epidemiology and etiology of pediatric ocular trauma. Surv Ophthalmol 2013;58(5):476-85.

3. Gogate P, Sahasrabudhe M, Shah M, et al. Causes, epidemiology, and long-term outcome of traumatic catarcts in children in rural India. Indian J Ophthalmol 2012; 60(5):481-6.

4. Neely D, Wilson E, Plager D, et al. Cataracts in Childhood. Orbis International. 2016. [Accessed on: March 7 $7^{\text {th }}$ 2017]. Available at: https://d1dk84hmsdb5u9.cloudfront. net / 991974c8-8e3f-431f-82ec-21b0fb7c92dc/Resources /
Cataracts $\% 20$ in $\% 20$ Children $\% 20$ Manual.pdf.

5. Shah M, Shah S, Applewar A, et al. Ocular Trauma Score as a predictor of final visual outcomes in traumatic cataract cases in pediatric patients. J Cataract Refract Surg 2012; 38(6):959-65.

6. Reddy A, Ray R, Yen K. Surgical intervention for traumatic cataracts in children: Epidemiology, complications, and outcomes. J AAPOS 2009;13(2):170-4.

7. Xu Y, Huang $Y$, Xie L. Pediatric traumatic cataract and surgery outcomes in eastern China: a hospital-based study. Int J Ophthalmol 2013;6(2):160-4.

8. Quezada-del Cid N, Zimmermann-Paiz M, OrdoñezRivas A. Características clínicas y epidemiológicas del trauma ocular en menores de 14 años. Arch Argent Pediatr 2015;113(5):e260-63.

9. Pons-Castro L, Arias-Díaz A, Naranjo Fernández R, et al. Resultadosdel tratamientoquirúrgicodelacatarata traumática en edad pediátrica. Rev Cuba Oftalmol 2010;23(2)209-218.

10. Razo-Blanco-Hernández DM, Pérez-Bastida XI, SánchezNava MF, et al. Estimación del daño por trauma ocular en pediatría sin la evaluación de la agudeza visual. Bol Med Hosp Infant Mex 2011;68(5):337-41.

11. Rumelt S, Rehany U. The influence of surgery and intraocular lens implantation timing on visual outcome in traumatic cataract. Graefes Arch Clin Exp Ophthalmol 2010;248(9):1293-7.

12. Shah M, Shah S, Upadhyay P, Agrawal R. Controversies in traumatic cataract classification and management: a review. Can J Ophthalmol 2013;48(4):251-8.

13. Shah M, Shah S, Shikhangi K, et al. Factors Affecting Visual Outcome Following Surgical Treatment of Cataracts in Children. Open J Ophthalmol 2012;2(4):131-9.

\title{
Prevalence of cow's milk protein allergy among children in a university community hospital
}

\author{
Romina Mehaudy, M.D. ${ }^{a, b}$, Claudio A.S. Parisi, M.D. ${ }^{c, b, f,}$, Natalia Petriz, M.D. ${ }^{c, b}$, Alfredo Eymann, M.D. ${ }^{d}$,
} María B. Jaureguie, B.S. ${ }^{b}$ and Marina Orsi, M.D. ${ }^{a, b}$

a. Department of Pediatric Gastroenterology

b. Food Allergies Interdisciplinary Service.

c. Division of Pediatric Allergy, Department of Clinical Pediatrics.

d. Department of Clinical Pediatrics.

e. Department of Nutrition.

Hospital Italiano de Buenos Aires.

f. Food Allergy Task Force of International Life Sciences Institute (ILSI), Argentina.

E-mail addres:

Claudio A.S. Parisi, M.D.: claudio.parisi@hospitalitaliano.org.ar

Funding: None.

Conflict of interest: None.

Received: 8-14-2017

Accepted: 10-26-2017

\begin{abstract}
Cow's milk protein allergy (CMPA) is the most common food allergy in pediatrics. In Argentina, the prevalence of this disease has been evaluated in a few trials.

Objectives. To estimate the prevalence of CMPA and describe its variation throughout a period of 11 years.

Population and methods. A retrospective cohort study was carried out in live newborn infants enrolled in a health care program of a university community hospital.

Results. Onehundred and sixteen cases of children with CMPA were identified. Cumulative prevalence was $0.8 \%$ (95\% confidence interval [CI]: $0.65-0.95$ ). A percent increase of $0.4 \%$ in 2004 to $1.2 \%$ in 2014 was observed in the number of cases per year. Conclusion. In 2014, CMPA prevalence was $1.2 \%$, i.e. three times that of 2004.

Key words: food allergy, cow milk, child, prevalence.
\end{abstract}

